\title{
Fredrik 0. Andersson* and Michael Ford Entry Barriers and Nonprofit Founding Rates: An Examination of the Milwaukee Voucher School Population
}

\author{
DOI 10.1515/npf-2016-0021
}

\begin{abstract}
In this study we examine how formal barriers to entry correlate with levels and changes in the founding rate of new voucher schools in Milwaukee. Drawing from a unique dataset covering founding attempts and successful foundlings of voucher schools since the early 1990s we show how formal institutions regulating entrepreneurial efforts have an impact on both attempts and success rates. For example, our analysis indicates that the removal of the non-sectarian school requirement led to an increase in entrepreneurial attempts. Likewise, we find that erecting of institutional barriers in the form of a formal third party approval process, proved to have an impactful effect on the founding success rate of new voucher schools. Our research also illuminate how a majority of entrepreneurial attempts, about 70 percent in the case of the new voucher schools in Milwaukee, fail somewhere between the stage of entrepreneur intent and actual establishment of the organization.
\end{abstract}

Keywords: founding rate, voucher schools, formal institutions, nonprofit entrepreneurship

\section{Introduction}

Although nonprofit entrepreneurship lacks a singular definition, a common characterization ties it closely to the formation and establishment of new nonprofit ventures (Bilodeau and Slivinski 1998; Cordes, Steuerle, and Twombly 2004; Haugh 2007). By this view, the pivotal nonprofit entrepreneurial event is the creation and operational launch of a nonprofit venture. The purpose of this paper is to examine how contextual conditions generate variations in the number of nonprofit foundings over time. Specifically, we investigate how institutional barriers to entry, primarily formal ones such as policies and regulations, have impacted the founding rate of nonprofit voucher schools in the City of

*Corresponding author: Fredrik 0. Andersson, Helen Bader Institute for Nonprofit Management, University of Wisconsin, Milwaukee, WI, USA, E-mail: andersso@uwm.edu

Michael Ford, University of Wisconsin Oshkosh, Oshkosh, WI, USA 
Milwaukee between 1990 and 2015. Institutions, the formal and informal rules of the game, are a vital component in modern entrepreneurship research as intuitions are viewed as having a significant influence on the allocation of entrepreneurial activities (Minniti 2008).

Formal institutions play a dual role for nonprofit entrepreneurs. Some constrain nonprofit entrepreneurial activity by creating and raising various types of entry barriers. Others establish conditions that help create windows of opportunity, and thus encouraging nonprofit entrepreneurial activity, for example, by removing or lowering entry barriers. Milwaukee was the first city in America to create a publicly funded private school voucher program in 1990 (Witte 2000), and therefore offers a unique setting for investigating the relation between institutional entry barriers and founding rates of an entire population. To be clear, formal institutions are not the only factor explaining variations in nonprofit founding rates, but as posited by Aldrich (1990), "institutional forces" are most likely to have their greatest impact on founding rates when "a new form of organization is emerging" as in the case of the Milwaukee voucher school population.

Although this paper only looks at one population of nonprofits in a localized market, we believe it can contribute to, and expand, the existing nonprofit entrepreneurship literature in important ways. First, this research illuminates and reinforces the significant role played by institutional factors, in addition to the characteristics and behaviors of the individual nonprofit entrepreneur, in shaping nonprofit entrepreneurship. Even though, as observed by Frumkin (2002, 130), “[o]ne of the principal reasons the nonprofit and voluntary sector is becoming an attractive vehicle for entrepreneurship is that the barriers to entry is low," nonprofit entrepreneurship research rarely studies population level phenomena, or how particular and/or changing institutional barriers impact entrepreneurial entry in the nonprofit sector. A better comprehension of the role and impact of such entry barriers is not just useful for nonprofit entrepreneurs, it is also valuable from a nonprofit entrepreneurship policy perspective. As highlighted by Harrison and Thornton (2014), policies are powerful tools for erecting (and/or removing) barriers to entry, and thereby having a direct impact on the supply of nonprofit entrepreneurs.

Second, our data covers all voucher schools in Milwaukee since the inception of the voucher program in 1990. Hence, rather than focusing on nonprofit entrepreneurship in the context of relatively stable and established populations this paper examines nonprofit entrepreneurship in a new and emerging population.

Third, not only does our data cover the entire Milwaukee voucher school population but also founding attempts of voucher schools in Milwaukee, which 
in turn allows us to analyze the actual founding rate of new nonprofit voucher schools. The founding rate can be depicted as the outcome of two underlying rates, each associated with a key stage in the start-up process of new organizations. The first is the rate at which attempts at founding are initiated; the second is the rate of success of those attempts (Delacroix and Carroll 1983). Thus, success in this second process is associated with the founding event itself and is to be distinguished from the success or failure of the organization once founded.

Because it is difficult to capture founding attempts, empirical nonprofit entrepreneurship research must typically rely on data of formally established nonprofits i. e. nonprofits that have been incorporated and/or received taxexempt status. The problem with this approach is that these organizations represent a culmination of the operation of both processes mentioned above. In other words, this data excludes those nonprofit entrepreneurs exiting the entrepreneurial process before being formally established. Thus, by utilizing the actual founding rate this paper is able to overcome the selection bias resulting from including only nonprofit entrepreneurial efforts that actually resulted in a formal new nonprofit organization.

\section{Background}

In his seminal article, Baumol (1990) makes the argument that while the supply of entrepreneurial agents are more or less constant, it is the nature of the institutions in which these agents are embedded that end up dictating the outcomes of entrepreneurial actions. Hence, by putting in place and/or attempt to alter institutions, policy makers can play a significant role in influencing various elements related to entrepreneurship. This idea is supported by Minniti (2008), who suggests that institutions, and the policies that shape them, are essential determinants of entrepreneurial behavior as "[g]overnment policies mold institutional structures for entrepreneurial action, encouraging some activities and discouraging others."

Nonprofit entrepreneurship scholars have indeed long emphasized the importance of institutional factors, such as policies and normative pressures, playing a potentially influential role for nonprofit entrepreneurial entry. (e. g., Young 1980; Schiff 1986; Bilodeau and Slivinski 1998; Cordes, Steuerle, and Twombly 2004; Steinberg 2006). In addition, one can find plenty of empirical literature looking into various aspects of nonprofit market entry (e.g., Corbin 1999; Saxton and Benson 2005; Harrison and Thornton 2014), yet relatively few 
inquiries have explicitly examined the relation between formal institutions and nonprofit entrepreneurship. One exception is Twombly (2003), who investigated the relation between the implementation of a federal welfare reform (the AFDC waiver program) and new nonprofit entry. He found the introduction of the reform initiative to be a highly significant determinant in explaining new nonprofit entry, and concluded that his study (p. 232) "[...] illustrates that policy initiatives such as welfare reform can substantially affect the composition of local human service sectors." Another example is Stephan, Uhlaner and Stride's (2015) interesting paper that examined the relationship between the institutional context and social enterprise start-ups (includes nonprofits as well as hybrid legal forms) in twenty-six countries. They find a positive relationship between government activism through the use of various forms of formal institutional support and social enterprise start-up activity, and conclude that "[o]ur findings on institutional configurations suggests that policymakers need to take formal and informal institutions into account when pondering policy decisions.”

\section{The Milwaukee Parental Choice Program (MPCP)}

The call for educational reform has often involved a significant institutional component. When Milton Friedman (1955) first formulated his idea of voucher schools as a way to improve education it was premised on creating an institutional framework that would stimulate and increase the supply of education entrepreneurs. Hess (2008) posits a stable and hospitable policy environment represents the foundation for establishing viable markets for educational entrepreneurship. Moreover, the focus of such policies must be to incentivize the creation of new schools (214): "In sector after sector, solving new problems-or more effectively addressing stubborn ones-has been the province of new entrants. Thus, the challenge is [...] to summon new ventures to build on fresh turf."

As the oldest and largest, and by some deemed most important (Epple, Romano, and Urquiola 2015), urban private school voucher program in the United States, the MPCP offers an outstanding case for exploring the role of institutions and nonprofit entrepreneurship. Not only is the Milwaukee voucher case unique in that it is well-established via its 26-year history, it has also been populated almost exclusively by non-profit organizations (Andersson and Ford 2015), and has generated large numbers of new entrants and large numbers of failed providers. Furthermore, there is growing recognition of the inconsistent performance of school choice programs, which has placed more emphasis on the 
need to study organizations providing alternative publicly funded educations as opposed to the mechanism by which a student ends up in a non-traditional school. In previous work, Ford and Andersson (2016) argue forcefully that the performance of hollow state activities built on social and/or nonprofit entrepreneurship is dependent on the strength or the organizations involved.

Since its start, the MPCP has been embedded in a range of formal institutional arrangements (Witte 2000). Over the life of the program the regulations governing MPCP schools evolved steadily. This policy evolution, detailed fully by Ford (2015b), is the foundation for our case analysis of the relationship between entry barriers and nonprofit entrepreneurship.

A sizable body of research has examined the impacts of the MPCP over its 26-year history (see Andersson and Ford 2016 for a review), but little research has targeted the relationship between new entrants and the evolving policy environment. To set the stage for our analysis, the next section outlines how a nonprofit entrepreneur would enter the Milwaukee education market.

\section{How a School Participates in the MPCP}

In this analysis, we exploit a unique program feature that allows us to capture data on attempted organizational entries into the MPCP, in addition to actual entries into the program i. e. successful attempts. Though the regulation of new schools has varied throughout the MPCP's history, the first required step for joining the program has remained consistent. Schools seeking to participate in the program are, under state law, required to file an "Intent to Participate Form" with the Wisconsin DPI no later than February 1st in the school year prior to their participation in the MPCP (Pugh 2015). For example, if a school wished to open in Fall of 2017 they would need to file their form by February 1st 2017. The form requires potential school operators to share the following information: (i) the name of their school; (ii) the address of their school, if known; (iii) the name and contact information of the school administrator; (iv) the months in which the school will accept application; and (v) the number of available voucher seats by grade.

The inclusion of the data on attempts allows us to examine two crucial features of nonprofit entrepreneurship. First, the filing of the "Intent to Participate Form" represents one of the earliest formal actions taken by a MPCP entrepreneur. Although filing the form is no guarantee the school will actually open, or enroll voucher pupils, it visibly and distinctly demonstrates intent on the part of the entrepreneur. Intent indicates more than mere desire, so while many individuals may indeed yearn to create a new voucher school, many 
never take further action and move beyond merely playing with the idea of starting a new organization. As a consequence, entrepreneurship scholars consider intentionality to signify one of the key properties of emerging organizations (Katz and Gartner 1988) i.e., an activity that takes place before an organization becomes an organization during the so-called nascent of gestation stage (Reynolds and Miller 1992). Thus, the data on attempts permits us to say something about the fundamental, yet scarcely researched, nascent stage of nonprofit entrepreneurship. Second, by capturing the number of attempted organizational entries into the MPCP we can also calculate and investigate the founding rate of new voucher schools. As outlined in the introduction, the founding rate captures two entrepreneurial processes, the rate at which individuals initiate attempts to start new schools, and a second rate depicting the success of those attempts, in the sense that a voucher school actually gets opened. According to Carroll and Khessina (2005), empirical research capturing both rates remains quite rare, and entrepreneurship scholars often assume that the two rates are closely connected, suggesting the rates move together in a consistent manner. But as Hannan and Carroll (1992) have pointed out, from an ecological perspective it is just as plausible to imagine the influence of environmental factors, for example formal institutions, that might propel one rate in one direction while carrying opposing implications for the other rate.

Ultimately, being able to observe both attempts and successful attempts to start new voucher schools brings an intriguing dimension to this research. Having highlighted how a nonprofit entrepreneur will participate in the MPCP we now move to examine the regulatory environment surrounding voucher schools in Milwaukee. In previous work (Andersson and Ford 2014; Ford and Andersson 2016) we have argued and demonstrated the key role environmental factors plays in the determining entry as well as existence of Milwaukee's voucher schools. In the subsequent section we turn our focus to variations over time in the founding rate of new voucher schools, and link these variations to the implementation of the various policy changes shaping the MPCP. By considering formal barriers to actually opening a new school, and how these barriers have evolved over the MPCP's history, we seek to discover policy relevant factors pertaining to the influence of these barriers on attempts as well as successful attempts to found new voucher schools.

\section{Data and Methodology}

As stated, the purpose of this article is to use the Milwaukee school voucher case to illustrate the relationship between barriers to entry, institutional factors, and 
organizational founding rates. We present our analysis as a case study meant to illustrate the nexus between public policy and nonprofit entrepreneurship. A case study approach offers many advantages. First, because we have 25 years of population data, inferential statistics are not appropriate. We are not attempting to use a sample to make conclusions about a population, but rather present a comprehensive case to demonstrate how public policies influence nonprofit entrepreneurship (Gerring 2004). Second, Gerring (2004) concludes that a case study is appropriate when one case can offer theoretical and/or practical insights to other cases. The MPCP is the rare example of a mature private school voucher program whose lessons can be applied to younger school choice programs in other locales, as well as other public policy initiatives designed to improve public performance through the encouragement of nonprofit entrepreneurship. Third, the organizational churn present in the Milwaukee voucher case presents an opportunity to test the previously discussed theories of nonprofit entrepreneurship.

We present the Milwaukee case using data on the attempted and successful openings of new voucher schools during different MPCP regulatory eras. The authors obtained all data from the Wisconsin Department of Public Instruction (DPI), Wisconsin's state education agency. Specifically, in spring of 2016, the authors requested copies of the annual DPI press release detailing the names and contact information for all schools that filed an Intent to Participate Form in each year of the MPCP's history. The authors then created a panel dataset where each observation was a new intended participant in the MPCP. Overall, DPI's releases indicate that between 1990 and 2015, 579 schools filed an initial Intent to Participate Form with the state of Wisconsin. However, not all of those schools were entrepreneurial efforts. The authors cross-checked all observations against previous data collected on MPCP schools (see: Anderson and Ford 2014) and determined that 128 of the 571 intended new MPCP participants were existing private schools (mostly Catholic and Lutheran). All existing schools were removed from the dataset.

Next, the authors used publicly available program enrollment data to determine which entrepreneurial attempts were successful. A successful attempt is defined as a school that filed an Intent to Participate Form and subsequently enrolled at least one MPCP pupil in the following school year. Overall, we find that 132 of the 443 entrepreneurial attempts, 29.8 percent, were successful. In addition, the data indicate that a sizable number of schools made multiple attempts; 43 schools filed forms twice, 12 filed forms three times, four filed forms four times, and three schools filed forms on five separate occasions. Importantly, schools that are successful at opening are not required to file an Intent to Participate form in subsequent school years. A majority of schools, 290, 
filed an Intent to Participate Form only once. Entrepreneurial attempts, successes, and success rates by year are displayed in Table 1, and Figures 1 and 2.

Table 1: Entrepreneurial attempts and successes by year.

\begin{tabular}{|c|c|c|c|c|}
\hline Year & Attempts & Opened Schools & Success Rate (\%) & Pct. Cap Used (\%) \\
\hline 1991 & 3 & 3 & 100.00 & 33.70 \\
\hline 1992 & 0 & 0 & $\mathrm{~N} / \mathrm{A}$ & 50.40 \\
\hline 1993 & 3 & 2 & 66.70 & 59.10 \\
\hline 1994 & 0 & 0 & N/A & 47.90 \\
\hline 1995 & 1 & 1 & 100.00 & 52.40 \\
\hline 1996 & 8 & 2 & 25.00 & 8.80 \\
\hline 1997 & 9 & 7 & 77.80 & 10.70 \\
\hline 1998 & 8 & 5 & 62.50 & 10.00 \\
\hline 1999 & 24 & 12 & 50.00 & 38.30 \\
\hline 2000 & 14 & 9 & 64.30 & 50.60 \\
\hline 2001 & 18 & 8 & 44.40 & 60.70 \\
\hline 2002 & 11 & 3 & 27.30 & 69.30 \\
\hline 2003 & 21 & 4 & 19.00 & 74.70 \\
\hline 2004 & 18 & 5 & 27.80 & 85.30 \\
\hline 2005 & 46 & 16 & 34.80 & 96.20 \\
\hline 2006 & 55 & 13 & 23.60 & 67.90 \\
\hline 2007 & 36 & 7 & 19.40 & 76.10 \\
\hline 2008 & 32 & 8 & 25.00 & 82.40 \\
\hline 2009 & 34 & 13 & 38.20 & 86.30 \\
\hline 2010 & 53 & 0 & 0.00 & 89.10 \\
\hline 2011 & 6 & 2 & 33.30 & 89.70 \\
\hline 2012 & 6 & 1 & 16.70 & N/A \\
\hline 2013 & 12 & 4 & 33.30 & N/A \\
\hline 2014 & 11 & 3 & 27.30 & $\mathrm{~N} / \mathrm{A}$ \\
\hline 2015 & 14 & 4 & 28.60 & $\mathrm{~N} / \mathrm{A}$ \\
\hline Total & 443 & 132 & 29.80 & $\mathrm{~N} / \mathrm{A}$ \\
\hline
\end{tabular}

Although school choice and school vouchers are often described as a freemarket approach to education, the term free does not imply there is no role or need for formal institutions to play. In fact, as discussed by Ford (2015b), the MPCP has, since its beginning, been embedded in a web of formal institutions, although the scope and nature of these institutions have changed several times during the quarter century the program has been operational. The changing regulatory climate was a direct result of public policy decisions enacted in response to perceived deficiencies in the MPCP. As can be seen in Table 1 and Figures 1 and 2, the number of entrepreneurial attempts and successes also 


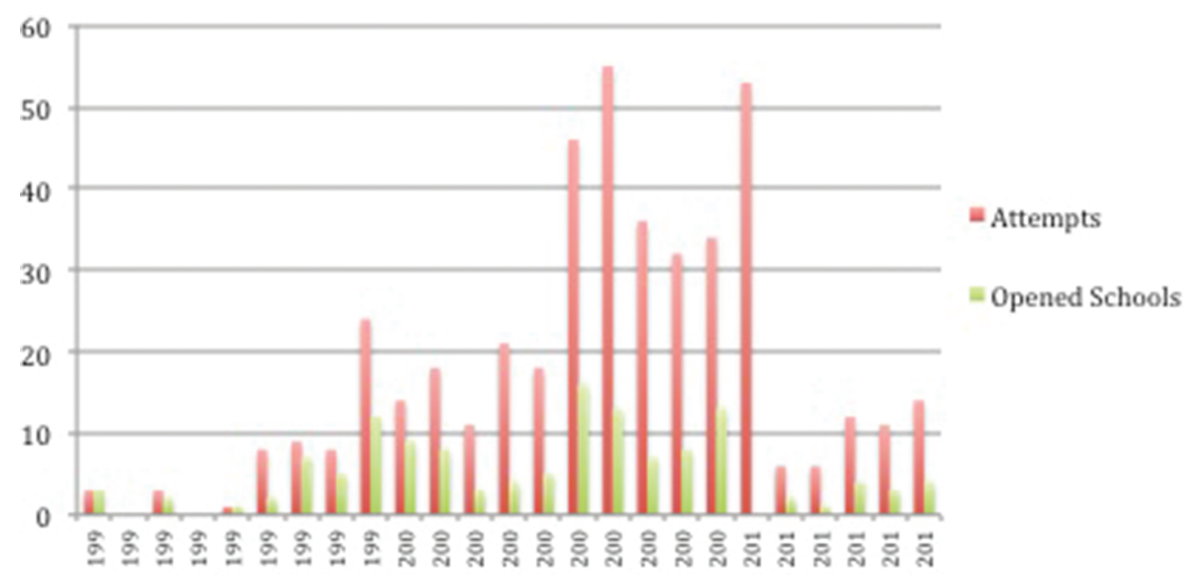

Figure 1: Entrepreneurial attempts and openings.

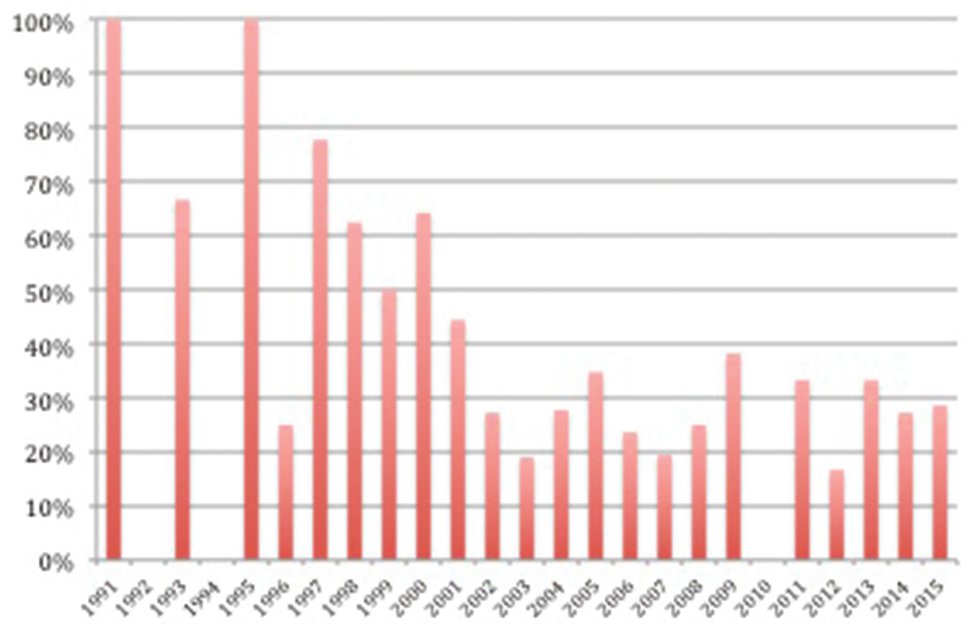

Figure 2: Entrepreneurial success rates.

fluctuated over the course of the program's history. In the following section we divide the MPCP into five distinct time periods, each of which represents a unique policy environment, and highlight the most significant institutional factors and/or changes present during each period. Finally, we demonstrate how the level of entrepreneurial activity fluctuated during each regulatory era in ways consistent with theory. 


\section{Entrepreneurship and the Changing MPCP Policy Environment}

\section{1-1995: Highly Restricted, Lightly Regulated}

When the MPCP was launched in 1990, it was with several stipulations attached. First, only non-sectarian schools were legally eligible to enroll pupils via the voucher program. Two, the program's overall enrollment was capped at 1,000 pupils from 1991 to 1993, and 1,500 pupils in 1994 and 1995 (in comparison MPS enrollment during that time was about 100,000 pupils). Third, schools were not allowed to enroll more than 49 percent of their pupils via vouchers. In such a highly restricted environment one would expect it to be exceptionally difficult for a new entrepreneur to enter the MPCP. Why? There was limited space for new providers due to the student enrollment cap, and the significant barrier to entry created by the need to attract a majority share of tuition-paying pupils. Not surprisingly, there were limited entrepreneurial attempts during this era.

However, the original MPCP was also lightly regulated. Schools did not have to meet any substantive academic or fiscal requirements. Thus, it is also not surprising that schools meeting the narrow eligibly criteria for MPCP participation were likely to succeed in opening their doors. As can be seen Table 1, six of the seven MPCP schools who intended to open between 1991 and 1995 did so successfully. Overall, the first five years of the MPCP show how a highly restricted entrepreneurial environment will be limited in size regardless of the regulations faced by organizations within said environment.

\section{6-1998: Decreased Restrictions, Lightly Regulated}

In the 1995-1996 school year the program enrollment cap was lifted to 15 percent of MPS enrollment, or about 15,000 students, and the 51 percent tuition-paying requirement was eliminated (Witte 2000; Pugh 2015). The two changes created more space for entrepreneurs to enroll voucher pupils, and removed a significant financial barrier to entry. Program regulations remained light during this period; however, the significant restriction created by the non-sectarian school requirement remained in place. Given these changes one would expect an overall modest increase in the number of entrepreneurial attempts, and continued high rate of successful school openings.

Indeed, as displayed in Table 1, a total of 25 schools attempted to open during this time period, and slightly over half, 14, were successful in doing so. 
Notably seven of the 11 unsuccessful school attempts occurred during the first year the overall program enrollment and school-level voucher-student cap was lifted. We suspect (though cannot confirm) the high rate of failed attempts in 1996 was a result of entrepreneurs rushing to take advantage of the loosened program restrictions without having fully appreciated what it would take to open a new school. Overall, this era demonstrates how reduced institutional barriers can enhance entrepreneurial activity, and that not all institutional barriers are equal; the non-sectarian school requirements ensured the program remained relatively small.

\section{9-2003: Few Restrictions, Lightly Regulated}

In 1998 the Wisconsin Supreme Court ruled that religious schools could participate in the MPCP (Pugh 2015). Given the historic role of religion in private education (both in Milwaukee and in general), the opening up of the MPCP to religious schools vastly increased available space for new providers (e.g., Coleman 1987; Dougherty 2004). Historically the advancement of religion was one motivating force behind the creation of private schools, and the majority of Milwaukee private schools (prior to 1991) were Catholic and Lutheran institutions (Witte 2000). In addition, at the time of the MPCP's founding the nonprofit organization Partners Advancing Values in Education (PAVE) was actively subsidizing religious education for low-income pupils in Milwaukee (Witte 2000). In other words, a large number of nonprofit religious schools were already adjusting their missions to serve low-income pupils, and eager to participate in the voucher program. In essence, the religious school exclusion created a soft but real enrollment cap on the MPCP, its repeal allowed the program to gain significant market-share.

As can be seen in Table 1, this era was characterized by a substantively significant uptick in entrepreneurial attempts, with 88 schools attempting to open between 1999 and 2003. The MPCP remained lightly regulated during this time period, and we expected to see high-rates of success as indicated by nascent schools actually opening their doors. However, just 36 of the 88 school attempts were successful. We suspect the declining rate of entrepreneurial success during the three eras (85.7 percent between 1991 and 1995, 56.0 percent between 1996 and 1998, and 40.9 percent between 1999 and 2003) in which regulation remained consistently light is a result of the increased entrepreneurial activity and competition for resources. Simply, when more entrepreneurs are attempting to enter a marketplace with finite resources, a smaller percentage is going to be successful. 


\section{4-2009: Growing Restrictions and Regulations}

Although modest barriers to entry had been in place since the MPCP's inception, the barriers did not substantively change until 2003 (Ford 2015b). Between 1991 and 2003, opening up a new school required little more than filing the Intent to Participate Form, finding a location, and attracting students. However, in response to quality concerns among program opponents and supporters, the Wisconsin legislature passed 2003 Act 155. The new act required new schools to produce evidence of fiscal viability, i. e. a budget, attend new schools training, and produce a City of Milwaukee occupancy permit before being allowed to participate in the MPCP (Pugh 2015). The quality concerns were spurred by media reports of dysfunction at two MPCP schools. The first, Alex's Academics of Excellence, was run by a convicted rapist. The second, Mandella Academy, was reported to be in a state of disarray by parents and reporters (Carr 2004). In both cases, DPI expressed frustration with their inability to take regulatory action against the schools, spurring the new barriers to entry supported by program supporters and opponents alike.

In 2005, the MPCP further evolved with the passage of legislation lifting the overall program enrollment cap to 22,500 students, requiring schools to obtain private accreditation within three years of program participation, and requiring schools to administer standardized tests of their choosing (Pugh 2015; Ford 2015b). The expanded program cap, increased barriers to entry, and growing regulatory burden during this era spurred high rates of entrepreneurial attempts, and a decreased success rate for would be schools. During this era, 62 out of 221 attempted schools, or 28.1 percent, were successful in opening their doors. As stated, we suspect the uptick in entrepreneurial attempts was a result of the increased program enrollment cap, while the lower success rate was a product of the increasing barriers to entry into the program, as well as the increased competition between nascent schools.

\section{0-2015: Increased Restrictions and Highly Regulated}

In response to concerns over new school quality, Wisconsin legislators passed legislation in 2009 establishing the new schools approval board at Marquette University. That board was charged with approving new private schools prior to their being allowed to participate in the MPCP (Pugh 2015). In 2011 the power to approve new schools was extended to other state-approved accreditation agencies (Pugh 2015). In addition, the 2009 law created an application fee, to go into effect in 2011, for all new schools (Pugh 2015). The annual fee, which was $\$ 1,317$ 
in 2011, funds an auditor position at DPI, and must be submitted with the Intent to Participate form. These two changes dramatically changed the calculus for potential new school entrepreneurs by requiring them to obtain approval from an outside entity, and to invest some of their own money into their entrepreneurial idea with no guarantee of success.

MPCP program regulations continued to increase between 2010 and 2016. MPCP schools were, for the first time, required to take and report the results of the Wisconsin state standardized test, and create and disseminate school policies in functional areas that conceptually mirrored those required of Wisconsin public schools (Pugh 2015; Ford 2015b). At the same time that program regulations increased, overall restrictions decreased with the elimination of the 22,500 total program enrollment cap, and the lifting of voucher pupil income eligibility requirements from 175 percent of the federal poverty level to 300 percent of the federal poverty level (Pugh 2015). Meaning, the MPCP, from 2010 to today, is a program for which there is nearly unlimited entrepreneurial space, but for which entry is highly restricted.

The result of the changed policy environment was a sharp decline in entrepreneurial activity. In 2010, all 53 potential new program participants were denied entry into the MPCP. In the five years that followed, the number of school entrepreneurs decreased to an average of about 10 per-year, compared to an average of about 37 per-year between 2004 and 2009. Success rates were also low, with just 13.7 percent of attempted new schools actually opening between 2010 and 2015. Interestingly, the current era of the MPCP demonstrates how the theorized positive impact of entrepreneurial space on entrepreneurial activity can be blunted by policies creating large barriers to entry for new participants. Whereas the previous increase in the enrollment cap in 2005 corresponded with increased entrepreneurial activity, there is no evidence the 2011 elimination of the enrollment cap spurred entrepreneurial activity (Pugh 2015).

Collectively, the different regulatory eras in the MPCP's history demonstrate the ways in which public policy changes impact nonprofit entrepreneurship. Throughout the MPCP's history increased space for new schools, signified by the elimination or curtailing of restrictions, generally increased program participation. The exception, of course, was when barriers to entry made it more difficult for new organizations to take advantage of the new space. Similarly, the level of program regulation, as well as the overall level of entrepreneurial activity within the voucher school sector, had a negative relationship with entrepreneurial success rates. Simply, when potentials entries into a marketplace face greater regulatory demands and competitive pressures, fewer will be successful. The greatest lesson from the Milwaukee 
voucher experience is the illustration of how public policy changes impact entrepreneurial activity and success in an ecosystem of nonprofit organizations that are highly dependent on government revenues.

\section{Conclusion and Discussion}

The research presented in this paper represents one of few known attempts to trace and analyze the founding rates of a specific nonprofit population over time. As commented by Carroll and Kessina (2005), many scholars tend to rely on either the rate of initiation of attempts or the rate of success of those attempts but seldom examine both at the same time. By combining data on attempts to start new voucher schools, and data on the number of successful start-ups emanating from these attempts, we offer a rare glimpse into the actual founding rate in a nonprofit population.

The key question examined in this paper is how formal barriers to entry correlate with levels and changes in the foundation rate of new voucher schools in Milwaukee. We examined this relation and are able to reveal how formal institutions regulating entrepreneurial efforts impact both entrepreneurial attempts, and success rates. Not surprisingly, we find that regulation that removes or lowers barriers to entry led to more entrepreneurial attempts to form new voucher schools. For example, by removing the non-sectarian school requirement, more space for entrepreneurs wanting to open religious schools opened up, and subsequently led to an increase in entrepreneurial attempts. Likewise, we find that erecting of institutional barriers, for example in the form of a formal third party approval process, proved to have an impact on the founding success rate of new voucher schools.

The size of the barrier presented by the formal third party approval process is, in many ways, an indictment of the qualifications of many of the entrepreneurs drawn to the voucher program prior to 2010. The initial review board located at the Institute for the Transformation of Learning at Marquette University, an organization headed by prominent voucher advocate Howard Fuller, denied every start-up school during its first year of operation (Witte 2000; Borsuk 2009). Fuller told the Milwaukee Journal Sentinel, "No matter how difficult it is and no matter how much disagreement it brings, we must focus on quality ... Dealing with barriers to entry is a very important part of that process" (Borsuk 2009). It was, in fact, concerns over school quality and need for barriers to entry that spurred a schism among long time voucher advocates in Milwaukee (Ford 2015b). Importantly, not much was known about the quality of 
voucher schools prior to the requirement for adding standardized tests, so the quality concerns were mostly anecdotal in nature.

In addition, we found that the creation and implementation of a modest fee for new schools dramatically decreased the level of attempted entrepreneurial activity, suggesting that pocket book issues can play a major role in determining the seriousness of entrepreneur intent. We were struck by the wide variation in the founding rate of voucher schools. Clearly, formal institutions are not the only factor impacting in the founding rate, but as noted in the introduction, institutions are considered as particularly pertinent when a new population is born and begins to develop. For example, although 2010 was a year when a considerable number of nonprofit entrepreneurs (53) attempted to create new voucher schools, not a single of these entrepreneurs were able to successfully launch a school. This can be compared to the year before when the success rate was approximately 40 percent. We can see few other explanations for this dramatic change in success rate than the erecting of entry barriers, such as the requirement obtain approval from an outside entity to start a school. It is important to remember that nonprofit voucher entrepreneurs, by seeking to enter a brand new industry, are different from those that can follow in the footsteps and tradition pioneered by numerous predecessors in the same industry. Thus, we agree with Aldrich's (1990) assertion that as new populations emerge and evolve, institutions will be "constraining and imprinting the new form in distinctive ways." Consequently, we suspect formal institutions are very much a relevant and potent source for explaining the, from time to time, notable changes in founding rates. Moreover, this research shows how formal institutions indeed can serve as powerful instruments for policy-makers to impact the allocation of nonprofit entrepreneurial action. While we have mainly looked at the creation and/or removal/lowering of entry barriers there are other ways for policy makers to influence this allocation process. For example, Stephan, Uhlaner, and Stride (2015) show how formal institutions sometimes take on an active and direct role by providing tangible (e.g., direct funding or subsidies) and intangible (e.g., administrative assistance) resource support, which end up affecting the supply of social entrepreneurs.

The demonstrated chilling effects of entry barriers and blunt nature of policy begs the question, are there ways to create and implement barriers to entry that prevent likely poor performing organizations from entering a marketplace without stymieing innovation? Put differently, can policy makers craft entry barriers screening prospective nonprofit entrepreneurs without discouraging the promising ones? The presented Milwaukee voucher case suggests it is impossible to totally eliminate the possibility of a poor-performing entrepreneurial school. Policy makers (as well as other stakeholder groups) can thus never ensure 
high performance, yet we believe there are policy steps to be taken to help reduce the chance for failure. First, new voucher school entrepreneurs could be required to demonstrate diverse revenue streams prior to be granted access to government revenues. This may include private fundraising dollars, evidence of private-paying customers, or reserves equal to a percentage of a school's budgeted revenues. These requirements would force a school to show evidence of viability beyond government revenues, and help ensure that a nascent school would not fail at the first sign of fiscal stress. Second, new entries could be required to find an existing organization to sponsor their entry into the marketplace. For example, if an entrepreneur wanted to open a new voucher school, he or she would first have to have to convince an existing provider of the soundness of their plan, and have that existing provider agree to enroll their pupils if the new school is not able to open. The risk, of course, is that existing providers would be fearful of competition and refuse to sponsor new schools. This concern could be addressed by offering a financial incentive for the sponsoring school based on the performance of the new school, or allowing third party accreditation agencies to serve as an alternative sponsor. Third, new entrepreneurs could be forced to submit to a state entity (in the voucher case the state board of education or its equivalent), and obtain approval from said entity, of a transition plan to ensure the organization's customers (i.e. students) and records are accounted for if the nascent organization fails to open, or opens and fails. While this would not prevent a school failure, it would minimize the externalities of a school failure without stopping entrepreneurship.

To answer are our own question, though it is impossible to prevent failed entrepreneurship, there are reasonable policies that can reduce the chances of failure, and mitigate the negative public impact of failure without eliminating entrepreneurial activity. It is important for policy makers to consider the context, however, when addressing failure risk. Policy makers should consider several questions. First, what is the public good being provided? The consequences of a failed school, for example, are greater than the consequences of a failed private provider of Department of Motor Vehicles services. Second, what is the public's tolerance for failure? This will depend on the political attitudes and culture of different policy environments. Third, what is the state's monetary investment in the entrepreneurial activity? In the voucher context the high level of public support creates significant financial consequences for the state when institutions fail. An entrepreneurial activity with minimal state investment may not need as much scrutiny from policy makers because the consequences of failure are less impactful on public coffers.

In this paper we have devoted little attention to such active formal institutions, nor have we taken into account the type of informal institutional factors 
with the power to shape and influence the founding rate e. g., prevailing norms and values, media coverage, or lobbying efforts. Future research is needed to examine a fuller spectrum of institutions and their impacts on the founding rate. A related question is how nonprofit entrepreneurs and other stakeholders are able to build legitimacy for voucher schools, and how this building process impacts the attempts as well as the founding success rate. The legitimacy question is particularly interesting because, as Aldrich and Fiol (1994) comments, entrepreneurs willing to venture in the formative years of a new industry are not just taking great risks, they may even be considered foolish. While the creation of formal institutions targeting the new industry will have some legitimizing properties, we still need to know more about what factors affects an emerging industry's legitimacy, and more on the specific legitimating strategies pursued by nonprofit voucher entrepreneurs.

Though this research only looks at one longstanding voucher program, we believe our analysis also illuminates a noteworthy facet of nascent stage nonprofit entrepreneurship, another seldom investigated topic in the nonprofit literature.

Anecdotal evidence suggests taking the step from being a nascent nonprofit entrepreneur to having a fledgling nonprofit is far from easy, and that the idea and intent of the nascent nonprofit entrepreneur peter out because their intentions were misguided or because they were unable to acquire a sizeable enough resource base to create a new organization. Thus, the nascent stage often end up being messy and hard to control due to various selection forces putting pressure on nascent nonprofit entrepreneur. Consequently, many attempts are believed to end in near misses, and fail before the formal nonprofit is launched. Because of the difficulty identifying and sampling nascent nonprofits we have little empirical understanding of nascent stage success and failure. The research presented in this paper demonstrates that a large majority of nonprofit entrepreneurial attempts, about 70 percent in the case of the MPCP, fail somewhere between the stage of entrepreneur intent and actual establishment of the organization. This finding thus lends support to the notion that, at any given time, we only observe only a surviving fraction of a much larger pool of nonprofit entrepreneurial efforts begun but abandoned by nascent nonprofit entrepreneurs. Clearly, nonprofit scholars need to pay more attention to the nascent stage to more fully comprehend the process of nonprofit entrepreneurship. As noted by Aldrich and Martinez (2001, 43):

Failure to appreciate the level of turnover and turbulence in populations has blinded social scientists and public policy experts to the organizational fermentation simmering just below the surface in modem societies. Past research has focused mainly on the prominent 
exceptions of organizations that manage to survive and grow, rather than the ubiquitous efforts that fail.

The finding that seven out of ten attempts to create new voucher schools fail tells us that a new formal nonprofit organization is just one possible outcome of nonprofit entrepreneurial activity. Furthermore, not only do most attempts to start new voucher schools in Milwaukee fail, of those succeeding in creating a new organization many will not succeed in sustaining the new school once formally created (Ford and Andersson 2016).

In summary, in this paper we have examined how the nonprofit entrepreneurial process associated with the creation of new voucher schools in the City of Milwaukee has been influenced and shaped by formal institutional arrangements. We find that formal institutions have impacted the founding rate of new voucher schools, thus, shaping the entry patterns of new voucher schools and those attempting to start new schools. However, this research has only scratched the surface, and more research is required to better understand the effects of formal as well as informal institutions and how they interact with the nonprofit entrepreneurship process. Research on other vouchers program, the entrepreneurs themselves, school performance, and the interactions and capital flows between start-up and existing voucher schools would help address the limits of our study.

\section{References}

Aldrich, H.E. 1990. "Using an Ecological Perspective to Study Organizational Founding Rates." Entrepreneurship Theory and Practice 14 (3):7-24.

Aldrich, H.E., and C.M. Fiol. 1994. "Fools Rush In? the Institutional Context of Industry Creation."." Academy of Management Review 19 (4):645-670.

Aldrich, H.E., and M.A. Martinez. 2001. "Many are Called, but Few are Chosen: An Evolutionary Perspective for the Study of Entrepreneurship." Entrepreneurship Theory and Practice 25 (4):41-56.

Andersson, F.O., and M. Ford. 2014. "Reframing Social Entrepreneurship Impact: Productive, Unproductive and Destructive Outputs and Outcomes of the Milwaukee School Voucher Program." Journal of Social Entrepreneurship 6 (3):299-319.

Andersson, F.O., and M. Ford. 2015. "Social Entrepreneurship through an Organizational Ecology Lens: Examining the Emergence and Evolution of the Voucher School Population in Milwaukee." VOLUNTAS: International Journal of Voluntary and Nonprofit Organizations 27 (4):1760-1780.

Andersson, F.O., and M. Ford. 2016. "Social Innovation in the Education Sector: A Review of the First 25 Years of The School Voucher Program in Milwaukee." Paper presented the 12th International Conference of the International Society for Third Sector Research (ISTR), June 28-July 1, Stockholm, Sweden. 
Baumol, W.J. 1990. “Entrepreneurship: Productive, Unproductive, and Destructive." The Journal of Political Economy 98 (5):893-921.

Bilodeau, M., and A. Slivinski. 1998. "Rational Nonprofit Entrepreneurship." Journal of Economics \& Management Strategy 7 (4):551-571.

Borsuk, A.J. 2009. “Just 3 New Voucher Schools Approved.” Milwaukee Journal Sentinel June 20, http://www.jsonline.com/news/education/51268272.html.

Carr, S. 2004. "State Bumps Two Schools in Milwaukee from Choice Program.” Milwaukee Journal Sentinel July 15.

Carroll, G.R., and O.M. Kessina. 2005. "The Ecology of Entrepreneurship.” In Handbook of Entrepreneurship Research: Disciplinary Perspectives, edited by S.A. Alvarez, R. Agarwal and O. Sorenson, 167-200. New York: Springer.

Coleman, J.S. 1987. “Families and Schools." Educational Researcher 16 (6):32-38.

Corbin, J.J. 1999. "A Study of Factors Influencing the Growth of Nonprofits in Social Services." Nonprofit and Voluntary Sector Quarterly 28 (3):296-314.

Cordes, J.J., C.E. Steuerle, and E. Twombly. 2004. "Dimensions of Nonprofit Entrepreneurship: An Exploratory Essay." In Public Policy and the Economics of Entrepreneurship, edited by D. Holtz-Eakin and H.S. Rosen, 115-152. Cambridge, MA: MIT Press.

Delacroix, J., and G.R. Carroll. 1983. "Organizational Foundings: An Ecological Study of the Newspaper Industries of Argentina and Ireland.” Administrative Science Quarterly 28: 274-291.

Dougherty, J. 2004. More than One Struggle: The Evolution of Black School Reform in Milwaukee. Chapel Hill, NC: University of North Carolina Press.

Epple, D., R.E. Romano, and M. Urquiola. 2015. School Vouchers: A Survey of the Economics Literature. Research Paper No. w21523. Cambridge, MA: National Bureau of Economic Research.

Ford, M. 2015b. "Nailing Shut the Policy Window: The Policy Evolution of America's First Urban School Voucher Program." Journal of Public and Nonprofit Affairs 1 (2):87-99.

Ford, M., and F.O. Andersson. 2016. "Organizational Failure in the Hollow State: Lessons from the Milwaukee Voucher Experience." International Journal of Public Administration doi. org/10.1080/01900692.2015.1053613.

Friedman, M. 1955. "The Role of Government in Public Education." In Economics and the Public Interest, edited by R.A. Solow, 123-144. New Brunswick, NY: Rutgers Press.

Frumkin, P. 2002. On Being Nonprofit: A Conceptual and Policy Primer. Boston, MA: Harvard University Press.

Gerring, J. 2004. "What Is a Case Study and What Is It Good For?" American Political Science Review 98 (02):341-354.

Hannan, M.T., and G.R. Carroll. 1992. Dynamics of Organizational Populations: Density, Legitimation, and Competition. New York: Oxford University Press.

Harrison, T., and J. Thornton. 2014. "Too Many Nonprofits? an Empirical Approach to Estimating Trends in Nonprofit Demand Density.” Nonprofit Policy Forum 5 (2):213-229.

Haugh, H. 2007. “Community-Led Social Venture Creation.” Entrepreneurship Theory and Practice 31 (2):161-182.

Hess, F.M. 2008. "The Supply Side of School Reform.” Phi Delta Kappan 90 (3):211-217.

Katz, J., and W.B. Gartner. 1988. "Properties of Emerging Organizations.” Academy of Management Review 13 (3):429-441.

Minniti, M. 2008. "The Role of Government Policy on Entrepreneurial Activity: Productive, Unproductive, or Destructive?." Entrepreneurship Theory and Practice 32 (5):779-790. 
Pugh, C. 2015. Private School Choice Programs. Madison, WI: Wisconsin Legislative Fiscal Bureau.

Reynolds, P.D., and B. Miller. 1992. "New Firm Gestation: Conception, Birth and Implications for Research." Journal of Business Venturing 7 (5):405-417.

Saxton, G.D., and M.A. Benson. 2005. "Social Capital and the Growth of the Nonprofit Sector." Social Science Quarterly 86 (1):16-35.

Schiff, J. 1986. Expansion, Entry and Exit in the Nonprofit Sector: The Long and Short Run of It. PONPO Working Paper 3. New Haven, CT: Yale University.

Steinberg, R. 2006. "Economic Theories of Nonprofit Organizations." In The Nonprofit Sector Handbook, 2nd edn, edited by W.W. Powell and R. Steinberg, 117-139. New Haven, CT: Yale University Press.

Stephan, U., L.M. Uhlaner, and C. Stride. 2015. "Institutions and Social Entrepreneurship: The Role of Institutional Voids, Institutional Support, and Institutional Configurations." Journal of International Business Studies 46 (3):308-331.

Twombly, E.C. 2003. "What Factors Affect the Entry and Exit of Nonprofit Human Service Organizations in Metropolitan Areas?" Nonprofit and Voluntary Sector Quarterly 32 (2):211-235.

Witte, J.F. 2000. The Market Approach to Education: An Analysis of America's First Voucher Program. Princeton, NJ: Princeton University Press.

Young, D.R. 1980. Entrepreneurship and the Behavior of Nonprofit Organizations: Elements of a Theory. PONPO Working Paper 4. New Haven, CT: Yale University. 